\title{
Effect of gefitinib on serum EGFR and CYFRA21-1 in patients with advanced non-small cell lung cancer
}

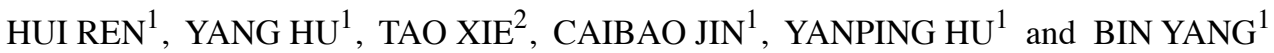 \\ Departments of ${ }^{1}$ Thoracic Oncology and ${ }^{2}$ Head and Neck Radiotherapy, \\ Hubei Cancer Hospital, Wuhan, Hubei 430079, P.R. China
}

Received May 9, 2019; Accepted July 1, 2019

DOI: $10.3892 / \mathrm{ol} .2019 .10762$

\begin{abstract}
Changes of epidermal growth factor receptor (EGFR) and cytokeratin fragment antigen 21-1 (CYFRA21-1) in patients with advanced non-small cell lung cancer (NSCLC) before and after gefitinib treatment were observed to explore the significance of such changes. A total of 175 patients with advanced NSCLC who were admitted to Hubei Cancer Hospital from July 2012 to October 2015 were collected and divided into two groups: the control group (85 patients who received conventional chemotherapy) and the experimental group (90 patients treated with gefitinib combined with chemotherapy). The serum expression levels of EGFR and CYFRA21-1 were detected by enzyme-linked immunosorbent assay (ELISA). The therapeutic efficacy and 3-year survival of the two groups were compared, and the factors affecting the survival of the patients were analyzed. The total effective rate and local effective rate of the experimental group were significantly higher than those of the control group $(\mathrm{P}<0.05)$. Before treatment, no significant difference was detected in the levels of EGFR and CYFRA21-1 between the two groups $(\mathrm{P}>0.05)$. After treatment, the expression levels of EGFR and CYFRA21-1 in the two groups were significantly lower than those before treatment $(\mathrm{P}<0.05)$. According to the 3 -year survival rate, the experimental group was divided into the survival group and the non-survival group. Single factor analysis was performed on the general data, showing that the influencing factors of the survival include the KPS score, smoking history, number of lesions, pathological stage, EGFR, and CYFRA21-1. Gefitinib can bring significantly improved therapeutic efficacy, lower expression levels of EGFR and CYFRA21-1, and longer survival time for patients with advanced NSCLC. Indicators including confirmed smoking history, a KPS score less than or equal to 60 points, multiple lesions, pathological stage IV, high expression of EGFR and
\end{abstract}

Correspondence to: Dr Bin Yang, Department of Thoracic Oncology, Hubei Cancer Hospital, 116 Zhoudao Quan South Road, Wuhan, Hubei 430079, P.R. China

E-mail: bn6g93@163.com

Key words: gefitinib, advanced non-small cell lung cancer, epidermal growth factor receptor, CYFRA21-1, influence
CYFRA21-1, are important factors affecting the survival of patient with advanced NSCLC.

\section{Introduction}

Lung cancer is the leading cause of cancer-related death worldwide (1). According to clinical statistical analysis of human cancer, non-small cell lung cancer (NSCLC), with an incidence rate of $85 \%$, and small cell lung cancer, with an incidence rate of $15 \%$, belong to different types (2), and the increasing incidence rate of NSCLC seriously jeopardizes human health $(3,4)$. Most NSCLC patients do not get the correct diagnosis until reaching the advanced stage, thus losing the best time for treatment $(5,6)$. Despite some progress in the treatment options of NSCLC in recent years, the prognosis for NSCLC is still very poor (7). Currently, radiotherapy, biological therapy, molecular targeted therapy, and chemotherapy are the main treatments for NSCLC $(8,9)$. The clinical application of epidermal growth factor receptor-tyrosine kinase inhibitors (EGFR-TKIs), one of the molecular targeted drugs that are widely used to treat advanced NSCLC after chemotherapy, surgery, and radiotherapy, has made breakthroughs in the treatment of NSCLC $(10,11)$.

Gefitinib, an oral molecular targeted drug, belongs to the class of aniline quinazolines. It is currently the first-line drug for patients with advanced NSCLC, with an anti-tumor effect mainly achieved through its competitive combination with EGFR $(12,13)$. Chemotherapy, as the main measure for the treatment of advanced NSCLC, can improve the quality of life, inhibit the growth of tumor cells in vivo, and prolong the survival period, but it causes great damage to the body function of patients and has many side effects (14). However, further research is needed on the specific efficacy of targeted drugs combined with chemotherapy in the treatment of advanced NSCLC. EGFR, a member of the type I transmembrane receptor protein tyrosine kinase Erb B family (15), its main function of mediated signal transduction, is closely related to tumor cell proliferation and differentiation regulation (16). The cytokeratin fragment antigen 21-1 (CYFRA21-1) is a tumor marker for detecting NSCLC, especially lung squamous cell carcinoma, mainly found in the cytoplasm of monolayer and pseudostratified epithelial cells (17).

This study mainly observed the changes of serum EGFR and CYFRA21-1 levels before and after gefitinib treatment, 
compared the clinical efficacy between the two groups, and explored the prognostic factors affecting the survival of patients with advanced NSCLC.

\section{Patients and methods}

General information. One hundred and seventy-five patients with advanced NSCLC, admitted to Hubei Cancer Hospital (Wuhan, China) from July 2012 to October 2015, were collected [85 patients receiving conventional chemotherapy enrolled in the control group (50 males and 35 females; a mean age of $60.17 \pm 8.78$ years, a duration of disease of $1.33 \pm 0.76$ years, including 53 cases of adenocarcinoma and 32 cases of squamous cell carcinoma), and 90 patients receiving gefitinib treatment combined with chemotherapy enrolled in the experimental group (54 males and 36 females; a mean age of $61.25 \pm 9.11$ years, a duration of disease of $1.46 \pm 0.86$ years, including 59 cases of adenocarcinoma and 31 cases of squamous cell carcinoma)].

Inclusion criteria: Patients confirmed with advanced NSCLC by cytology and histology; patients not receiving other recent anti-tumor treatments; patients with no serious vascular invasion according to the imaging examination; and patients with an expected survival time of more than 3 months.

Exclusion criteria: Patients who failed to complete the treatment plan due to a strong request for withdrawal or loss of follow-up or other reasons; patients with chemotherapy contraindications; patients with autoimmune system defects; pregnant or lactating female patients; patients with poor compliance during treatment; and patients stopping the treatment due to adverse reactions or intolerance.

With a detailed description of the experimental content, this study was approved by the Ethics Committee of Hubei Cancer Hospital. All the subjects signed a complete informed consent form and had complete clinical data.

Treatment plan. The control group received conventional chemotherapy: pemetrexed (Eli Lily and Company; medical product permitted by the China Food and Drug Administration, no. H20100060) at a dose of $500 \mathrm{mg} / \mathrm{m}^{2}$ and cisplatin (Jiangsu Hansoh Pharmaceutical Group Co., Ltd.; medical product permitted by the China Food and Drug Administration, no. H20040812) at a dose of $75 \mathrm{mg} / \mathrm{m}^{2}$ were given from the first day of chemotherapy, and the treatment lasted for continuous 4 to 6 courses, with 21 days marking a treatment course. On the basis of chemotherapy, patients in the experimental group were also treated with a molecular targeted drug: gefitinib [AstraZeneca (Wuxi) Trading Co., Ltd., medical product permitted by the China Food and Drug Administration, no. J20070047] was orally administered at a dose of $250 \mathrm{mg}$ per day according to the condition with the same treatment duration as the control group, and the efficacy was evaluated after treatment. The patient's performance and adverse reactions were closely monitored, and the disease control and cancer cell size changes were recorded regularly. The drug administration was stopped as a result of disease progression or intolerance.

Serum specimen collection. Fasting elbow venous blood (4 ml) was taken from all experimental subjects in the morning at $24 \mathrm{~h}$ before treatment and $24 \mathrm{~h}$ after treatment, and then the blood was centrifuged at $2,600 \mathrm{x}$ g for $15 \mathrm{~min}$ at $4^{\circ} \mathrm{C}$. The slurry in the test tube was carefully absorbed to collect the serum which was then stored in a freezer at $-20^{\circ} \mathrm{C}$ and tested by a designated person.

Detection of serum EGFR, CYFRA21-1 expression levels by enzyme-linked immunosorbent assay (ELISA). ELISA was performed to detect the serum EGFR, CYFRA21-1 expression levels. The EGFR kit and CYFRA21-1 kit were provided by Jiangsu Baolai Biotechnology Co., Ltd. (batch nos. MM-1698H1, MM-1113H2). The BS-1101 enzyme label analyzer was purchased from Beijing Linmao Technology Co., Ltd. The sample well, standard well and blank control well were separately set, and $50 \mu 1$ of the sample was accurately added to the standard well on the enzyme label coated plate, $40 \mu \mathrm{l}$ of the sample dilution and $10 \mu \mathrm{l}$ of the sample were added to the sample well. Caution was taken during the operation to avoid touching the wall as far as possible, and the plate was jiggled. The plate was then sealed with a sealing film and incubated at $37^{\circ} \mathrm{C}$ for $30 \mathrm{~min}$. After that, the sealing film was carefully uncovered and the liquid was discarded, then the wells were dried with absorbent paper then filled with the washing solution. After standing for $30 \mathrm{sec}$, the discarding and refilling were repeated five times and the wells were finally patted dry. Each well, except for the blank wells, was added with $50 \mu \mathrm{l}$ of the enzyme labeling reagent. Then, $50 \mu \mathrm{l}$ of developer A and $50 \mu \mathrm{l}$ of developer B were sequentially added to every well and mixed, away from light at $37^{\circ} \mathrm{C}$ for $15 \mathrm{~min}$. Next, $50 \mu 1$ of the stop solution was added to each well to terminate the reaction, and yellow color appeared in the wells. Within $15 \mathrm{~min}$, with the blank well as the zero reference value, the OD value of each well was measured at a wavelength of $450 \mathrm{~nm}$. A standard curve was used to calculate the concentration of EGFR and CYFRA21-1 in the sample. All operations were in strict accordance with manufacturer's instructions.

Efficacy evaluation criteria (18). The evaluation was accoding to the response evaluation criteria in solid tumors (RECIST). Complete remission (CR): all lesions disappear and the situation is maintained for 1 month; partial remission (PR): total lesion diameter is reduced by equal or $>30 \%$ and the situation is maintained for 1 month; progressive disease (PD): total diameter of lesion increases by equal or $>20 \%$ or new lesions appear; stable disease (SD): the reduction of total diameter of the lesion is smaller than PR or the increase of total diameter of the lesion is smaller than PD. Effective rate $=(C R$ case number + PR case number)/total case number $\times 100 \%$. Local tumor control rate $=(\mathrm{CR}$ case number $+\mathrm{PR}$ case number $+\mathrm{SD}$ case number)/total case number.

Grouping according to the total effective rate: effective group = complete remission group + partial remission group; invalid group $=$ stable disease group + progressive disease group .

Follow-up and observation indicators. Regular follow-up was conducted by subsequent consultation with doctors and by telephone interviews. The 3-year survival of the two groups of patients after treatment was recorded. The treatment effect was evaluated according to the World Health Organization (WHO) response evaluation criteria in solid tumors, and the overall efficacy was recorded. Disease mutation during the follow-up was promptly treated, and the examination was strengthened every time. The survival time was recorded from the first day 
Table I. Comparison of the general information between the two groups (mean $\pm \mathrm{SD}) /[\mathrm{n}(\%)]$.

\begin{tabular}{|c|c|c|c|c|}
\hline Clinical factors & Experimental group $(\mathrm{n}=90)$ & Control group $(\mathrm{n}=85)$ & $\chi^{2} / \mathrm{t}$ value & P-value \\
\hline Sex & & & 0.025 & 0.874 \\
\hline Male & $54(60.0)$ & $50(58.8)$ & & \\
\hline Female & $36(40.0)$ & $35(41.2)$ & & \\
\hline Average year & $61.25 \pm 9.11$ & $60.17 \pm 8.78$ & & \\
\hline Weight (kg) & & & 0.286 & 0.593 \\
\hline$<50$ & $21(23.3)$ & $17(20.0)$ & & \\
\hline$\geq 50$ & 69 (76.7) & $68(80.0)$ & & \\
\hline Smoking & & & 0.001 & 0.979 \\
\hline Yes & $39(43.3)$ & 37 (43.5) & & \\
\hline No & $51(56.7)$ & $48(56.5)$ & & \\
\hline Drinking & & & 0.206 & 0.650 \\
\hline Yes & $57(63.3)$ & $51(60.0)$ & & \\
\hline No & $33(36.7)$ & $34(40.0)$ & & \\
\hline KPS score & & & 0.078 & 0.780 \\
\hline$\leq 60$ & $50(55.6)$ & 49 (57.6) & & \\
\hline$>60$ & $40(44.4)$ & $36(42.4)$ & & \\
\hline Duration of disease (year) & $1.46 \pm 0.86$ & $1.33 \pm 0.76$ & 1.057 & 0.292 \\
\hline Tumor size $(\mathrm{cm})$ & & & 0.043 & 0.836 \\
\hline$\leq 3$ & $42(46.7)$ & $41(48.2)$ & & \\
\hline$>3$ & $48(53.3)$ & $44(51.8)$ & & \\
\hline Pathological type & & & 0.195 & 0.659 \\
\hline Adenocarcinoma & $59(65.6)$ & $53(62.4)$ & & \\
\hline Squamous cell carcinoma & $31(34.4)$ & $32(37.6)$ & & \\
\hline Number of lesions & & & 0.116 & 0.733 \\
\hline Single & $34(37.8)$ & $30(35.3)$ & & \\
\hline Multiple & $56(62.2)$ & $55(64.7)$ & & \\
\hline Pathological stage & & & 0.049 & 0.825 \\
\hline IIIB & $30(33.3)$ & $27(31.8)$ & & \\
\hline IV & $60(66.7)$ & $58(68.2)$ & & \\
\hline
\end{tabular}

of treatment to the death or the last day of follow-up. The last day of follow-up was October 5, 2018.

Statistical analysis. The experimental data were statistically analyzed using SPSS 17.0 statistical software (SPSS Inc.); $\mathrm{n}(\%)$ indicates enumeration data, which was compared between the two groups using the Chi-square test; (mean \pm SD) indicates measurement data, which was compared between the two groups using an independent sample t-test; and a paired t-test was used for comparison between the situation before and after treatment. Survival analysis of the two groups was performed using the Kaplan-Meier method and compared using the log-rank test, and Cox regression was used to analyze the independent prognostic factors of NSCLC patients. A statistical difference was recognized at $\mathrm{P}<0.05$.

\section{Results}

Comparison of the general information between the two groups. According to the general information of the two groups shown in Table I, both the experimental and control groups were comparable since the two groups of patients were not significantly different in terms of sex, age, weight, smoking and drinking, KPS score, duration of disease, tumor size, pathological type, number of lesions, and pathological stage $(\mathrm{P}>0.05)$.

Comparison of clinical efficacy between the two groups. The experimental group had an effective rate of $66.7 \%$ and a local tumor control rate of $87.8 \%$, including 24 cases of CR, 36 cases of PR, 19 cases of SD, and 11 cases of PD. The control group showed an effective rate of $34.1 \%$ and a local tumor control rate of $68.2 \%$, with 10 cases of CR, 19 cases of PR, 29 cases of SD, and 27 cases of PD. The total effective rate and local effective rate of the experimental group were significantly higher than those of the control group $(\mathrm{P}<0.05)$ (Table II).

Changes in the concentration of EGFR and CYFRA21-1 before and after treatment in both groups (Figs. 1 and 2). Before treatment, the expression levels of EGFR and CYFRA21-1 in the 
Table II. Comparison of clinical efficacy between the two groups [n (\%)].

\begin{tabular}{lccccccc}
\hline Groups & no. & CR & PR & SD & PD & Effective rate & $\begin{array}{c}\text { Local tumor } \\
\text { control rate }\end{array}$ \\
\hline Experimental group & 90 & $24(26.7)$ & $36(40.0)$ & $19(21.1)$ & $11(12.2)$ & $66.7 \%$ & $87.8 \%$ \\
Control group & 85 & $10(11.8)$ & $19(22.3)$ & $29(34.1)$ & $27(31.8)$ & $34.1 \%$ & $68.2 \%$ \\
$\chi^{2}$ value & & & & & & 21.78 & 11.66 \\
P-value & & & & & & $<0.001$ & 0.0006 \\
\hline
\end{tabular}

$\mathrm{CR}$, complete remission; PR, partial remission; SD, stable disease; PD, progressive disease.

Table III. The serum levels of tumor markers in the subgroups of the experimental group before and after treatment.

\begin{tabular}{lcccccc}
\hline & & \multicolumn{2}{c}{ EGFR(ng/l) } & & \multicolumn{2}{c}{ CYFRA21-1(ng/ml) } \\
\cline { 3 - 4 } \cline { 6 - 7 } Groups & Case no. & $\begin{array}{c}\text { Before } \\
\text { treatment }\end{array}$ & $\begin{array}{c}\text { After } \\
\text { treatment }\end{array}$ & & $\begin{array}{c}\text { Before } \\
\text { treatment }\end{array}$ & $\begin{array}{c}\text { After } \\
\text { treatment }\end{array}$ \\
\hline Effective group & 60 & $24.35 \pm 5.77$ & $11.89 \pm 3.65^{\mathrm{a}}$ & & $10.87 \pm 2.98$ & $3.09 \pm 0.08^{\mathrm{a}}$ \\
Ineffective group & 30 & $24.01 \pm 5.91$ & $25.27 \pm 7.97$ & & $10.78 \pm 2.77$ & $9.92 \pm 2.09$ \\
t value & & 0.269 & 10.60 & & 0.181 & 13.71 \\
P-value & & 0.788 & $<0.001$ & & 0.857 & $<0.001$ \\
\hline
\end{tabular}

${ }^{\mathrm{a}} \mathrm{P}<0.05$, when compared with the data before treatment.

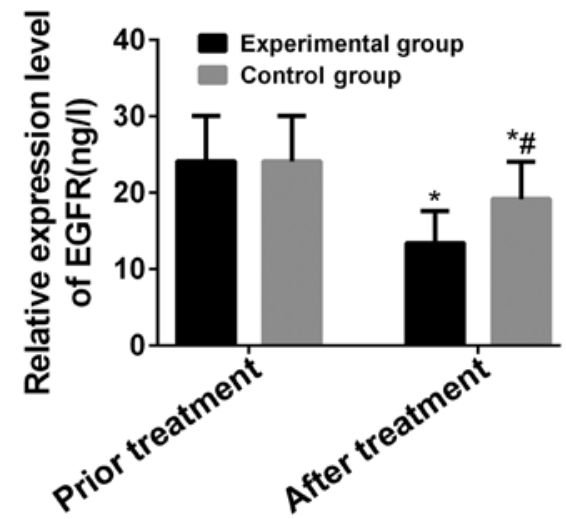

Figure 1. Changes in the concentration of EGFR before and after treatment. Before treatment, no significant difference was detected in the concentration of EGFR between the experimental and control groups $(\mathrm{P}>0.05)$. After treatment, the expression levels of EGFR both in the experimental and control groups were significantly lower than those in the two groups before treatment $(\mathrm{P}<0.05)$, with much lower expression level of EGFR in the experimental group than in the control group, and the differences were statistically significant $(\mathrm{P}<0.05) .{ }^{*} \mathrm{P}<0.05$, when compared with the data before treatment; ${ }^{\#} \mathrm{P}<0.05$, when compared with the data of the experimental group after treatment.

experimental group were $24.13 \pm 5.87 \mathrm{ng} / \mathrm{l}$ and $10.98 \pm 3.02 \mathrm{ng} / \mathrm{ml}$, the expression levels of EGFR and CYFRA21-1 in the control group were $24.09 \pm 5.91 \mathrm{ng} / \mathrm{l}$ and $10.82 \pm 2.91 \mathrm{ng} / \mathrm{ml}$, with no significant difference being detected between the experimental and control groups $(\mathrm{P}>0.05)$. After treatment, the expression levels of EGFR and CYFRA21-1 in the experimental group were $13.37 \pm 4.21 \mathrm{ng} / \mathrm{l}$ and $6.27 \pm 2.12 \mathrm{ng} / \mathrm{ml}$, statistically lower than those of the control group (expression level of EGFR

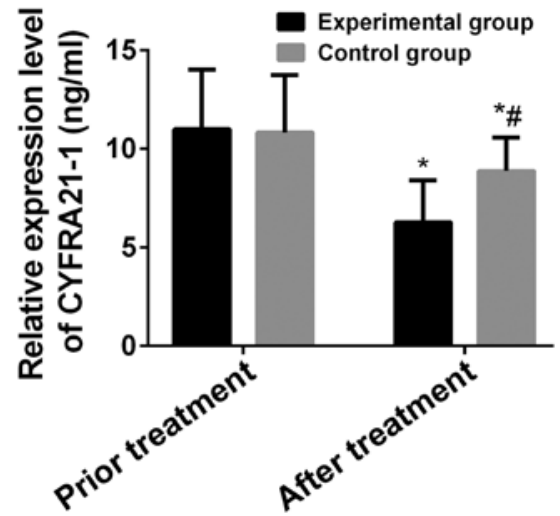

Figure 2. Changes in the concentration of CYFRA21-1 before and after treatment. Before treatment, no significant difference was detected in the concentration of CYFRA21-1 between the experimental and control groups (P>0.05). After treatment, the expression levels of CYFRA21-1 both in the experimental and control groups were significantly lower than those in the two groups before treatment $(\mathrm{P}<0.05)$, with much lower expression level of CYFRA21-1 in the experimental group than in the control group, and the differences were statistically significant $(\mathrm{P}<0.05)$. ${ }^{*} \mathrm{P}<0.05$, when compared with the data before treatment. ${ }^{\#} \mathrm{P}<0.05$, when compared with the data of the experimental group after treatment.

at $19.14 \pm 4.87 \mathrm{ng} / 1$ and expression level of CYFRA21-1 at $8.87 \pm 1.68 \mathrm{ng} / \mathrm{ml})(\mathrm{P}<0.05)$, and both groups had much lower expression levels of EGFR and CYFRA21-1 after treatment than those before treatment $(\mathrm{P}<0.05)$.

The serum levels of EGFR and CYFRA21-1 in the subgroups of the experimental group before and after treatment. Before 
Table IV. Comparison of general information between the survival and non-survival groups of the experimental group [n (\%)].

\begin{tabular}{|c|c|c|c|c|}
\hline Clinical factors & Survival group $(n=27)$ & Non-survival group $(\mathrm{n}=63)$ & t value & P-value \\
\hline Sex & & & 0.141 & 0.707 \\
\hline Male & $17(63.0)$ & $37(58.7)$ & & \\
\hline Female & $10(37.0)$ & $26(41.3)$ & & \\
\hline Age (year) & & & 0.729 & 0.393 \\
\hline$<50$ & $12(44.4)$ & $22(34.9)$ & & \\
\hline$\geq 50$ & $15(55.6)$ & $41(65.1)$ & & \\
\hline Weight (kg) & & & 0.027 & 0.870 \\
\hline$<50$ & $6(22.2)$ & $15(23.9)$ & & \\
\hline$\geq 50$ & $21(77.8)$ & $48(76.2)$ & & \\
\hline Duration of disease (year) & & & 2.168 & 0.141 \\
\hline$\leq 2$ & $17(63.0)$ & $29(46.0)$ & & \\
\hline$>2$ & $10(37.0)$ & $34(54.0)$ & & \\
\hline Smoking & & & 16.31 & $<0.001$ \\
\hline Yes & $3(11.1)$ & $36(57.1)$ & & \\
\hline No & $24(88.9)$ & $27(42.9)$ & & \\
\hline Drinking & & & 2.190 & 0.139 \\
\hline Yes & $14(51.9)$ & $43(68.3)$ & & \\
\hline No & $13(48.1)$ & $20(31.7)$ & & \\
\hline KPS score & & & 17.36 & $<0.001$ \\
\hline$\leq 60$ & $6(22.2)$ & $44(69.8)$ & & \\
\hline$>60$ & $21(77.8)$ & $19(30.2)$ & & \\
\hline Tumor size (cm) & & & 0.077 & 0.782 \\
\hline$\leq 3$ & $12(44.4)$ & $30(47.6)$ & & \\
\hline$>3$ & $15(55.6)$ & $33(52.4)$ & & \\
\hline Pathological type & & & 0.677 & 0.411 \\
\hline Adenocarcinoma & $16(59.3)$ & $43(68.3)$ & & \\
\hline Squamous cell carcinoma & $11(40.7)$ & $20(31.7)$ & & \\
\hline Number of lesions & & & 13.69 & 0.0002 \\
\hline Single & $18(66.7)$ & $16(25.4)$ & & \\
\hline Multiple & $9(33.3)$ & $47(74.6)$ & & \\
\hline Pathological stage & & & 11.67 & 0.0006 \\
\hline IIIB & $16(59.3)$ & $14(22.2)$ & & \\
\hline IV & $11(40.7)$ & $49(77.8)$ & & \\
\hline EGFR (ng/l) & & & 10.41 & 0.001 \\
\hline High expression & $10(37.0)$ & $46(73.0)$ & & \\
\hline Low expression & $17(63.0)$ & $17(27.0)$ & & \\
\hline CYFRA21-1 (ng/ml) & & & 13.69 & 0.0002 \\
\hline High expression & $9(33.3)$ & $47(74.6)$ & & \\
\hline Low expression & $18(66.7)$ & $16(25.4)$ & & \\
\hline
\end{tabular}

EGFR, epidermal growth factor receptor; CYFRA21-1, cytokeratin fragment antigen 21-1.

treatment, no significant difference was detected in the levels of EGFR and CYFRA21-1 between the effective and ineffective groups $(\mathrm{P}>0.05)$. The serum expression levels of EGFR and CYFRA21-1 in the effective group after treatment were significantly lower than those before treatment $(\mathrm{P}<0.05)$. The serum expression levels of EGFR and CYFRA21-1 in the ineffective group were not significantly different from those before treatment. After treatment, the levels of EGFR and CYFRA21-1 in the effective group were significantly lower than those in the ineffective group $(\mathrm{P}<0.05)$ (Table III).

Comparison of survival analysis between the experimental and control groups. The follow-up and the comparison of survival between the two groups as shown in Fig. 3, the 
Table V. Variable name and assignment.

\begin{tabular}{|c|c|c|c|c|c|}
\hline \multicolumn{3}{|l|}{ Factors } & \multicolumn{3}{|c|}{ Assignment } \\
\hline \multicolumn{3}{|l|}{ KPS score } & \multicolumn{3}{|c|}{$\leq 60: 1,>60: 2$} \\
\hline \multicolumn{3}{|l|}{ Smoking } & \multicolumn{3}{|c|}{ Yes: 1, no: 2} \\
\hline \multicolumn{3}{|l|}{ Number of lesions } & \multicolumn{3}{|c|}{ Single: 1 , multiple: 2} \\
\hline \multicolumn{3}{|l|}{ Pathological stage } & \multicolumn{3}{|c|}{ IIIB: 1, IV: 2} \\
\hline \multirow{2}{*}{\multicolumn{3}{|c|}{$\begin{array}{l}\text { EGFR (ng/l) } \\
\text { CYFRA21-1 (ng/ml) }\end{array}$}} & \multirow{2}{*}{\multicolumn{3}{|c|}{$\begin{array}{l}\text { High expression }(\geq 13.37 \mathrm{ng} / \mathrm{l}): 1 \text {, low expression }(<13.37 \mathrm{ng} / \mathrm{l}): 2 \\
\text { High expression }(\geq 6.27 \mathrm{ng} / \mathrm{ml}): 1 \text {, low expression }(<6.27 \mathrm{ng} / \mathrm{ml}): 2\end{array}$}} \\
\hline & & & & & \\
\hline \multicolumn{6}{|c|}{ EGFR, epidermal growth factor receptor; CYFRA21-1, cytokeratin fragment antigen 21-1. } \\
\hline \multicolumn{6}{|c|}{ Table VI. Multivariate analysis of factors affecting the prognosis in patients with advanced NSCLC. } \\
\hline Factors & $\beta$ & $\mathrm{SD}$ & $\chi^{2}$ value & P-value & $\mathrm{HR}(95 \% \mathrm{CI})$ \\
\hline KPS score & -1.847 & 0.875 & 4.458 & 0.035 & $0.158(0.028-0.876)$ \\
\hline Smoking & -3.065 & 1.072 & 8.171 & 0.004 & $0.047(0.006-0.382)$ \\
\hline Number of lesions & 2.470 & 0.967 & 6.525 & 0.011 & $11.820(1.777-78.636)$ \\
\hline Pathological stage & 2.467 & 0.928 & 7.064 & 0.008 & $11.782(1.911-72.638)$ \\
\hline EGFR (ng/l) & -2.221 & 0.906 & 6.007 & 0.014 & $0.109(0.018-0.641)$ \\
\hline CYFRA21-1 (ng/ml) & -2.535 & 0.933 & 7.391 & 0.007 & $0.079(0.013-0.493)$ \\
\hline
\end{tabular}

EGFR, epidermal growth factor receptor; CYFRA21-1, cytokeratin fragment antigen 21-1; NSCLC, non-small cell lung cancer.

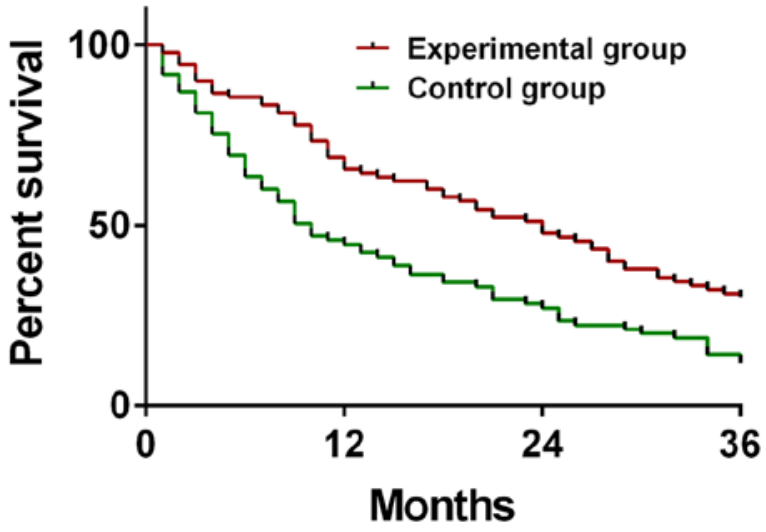

Figure 3. Comparison of the survival analysis between the experimental and control groups. The follow-up and the comparison of survival between the two groups showed the 3-year survival rate of the experimental group after treatment was $30.0 \%$, much higher than the survival rate of $11.8 \%$ in the control group, and the difference was statistically significant $(\mathrm{P}<0.05)$.

3-year survival rate of the experimental group after treatment was $30.0 \%$, much higher than the survival rate of $11.8 \%$ in the control group, and the difference was statistically significant $(\mathrm{P}<0.05)$.

Logistic regression analysis of survival and non-survival in the experimental group. According to the 3-year survival rate, the experimental group was divided into the survival group and the non-survival group. The single factor analysis was performed on the general data, showing that the influencing factors of the survival include the KPS score, smoking history, number of lesions, pathological stage, EGFR, and CYFRA21-1. Subsequently, the multivariate Cox regression analysis of different indicators showed that confirmed smoking history, a KPS score less than or equal to 60 points, multiple lesions, pathological stage IV, high expression of EGFR and CYFRA21-1 were important factors affecting the survival of advanced NSCLC (Tables IV-VI).

\section{Discussion}

The faster pace of life and environmental pollution have led to an increasing case number of sub-health, which, in the long run, may easily cause a variety of diseases, such as lung cancer, one of the most common malignant tumors worldwide, that attracts the focus of clinical attention due to its difficult diagnosis in early stage (19). Most patients with NSCLC do not get the correct diagnosis until reaching the locally advanced stage when distant metastasis or invasion of important surrounding organs occurs, making surgical treatment impossible (20). Advanced NSCLC is mainly treated by targeted therapy (21). Gefitinib, the most effective targeted drug for NSCLC, achieves its inhibition on tumor cell proliferation and division mainly by the contribution of EGFR-TKI to block the signal transduction of cellular proliferation (22).

EGFR is mainly present in the monomeric form on the cell membrane, and needs to be activated by its ligand and other ErbB family members, such as transforming growth factor- $\alpha$, epidermal growth factor and amphiregulin, since its monomer is not active (23). With the conformation changes achieved by the binding of its ligands to receptors, EGFR can mediate 
the proliferation, differentiation, metastasis, invasion, and the inhibition of apoptosis of tumor cells. The receptors can form heterodimers with other members of the EGFR family or form homodimers by themselves, which activates the tyrosine kinase domain to trigger autophosphorylation and transphosphorylation to form pEGFR to activate a cascade of downstream enzymatic signaling pathways that transmit signals to the nucleus (24-26). CYFRA21-1, an intermediate fiber between tumor cytoskeletal proteins and normal cells that exists in the cytoplasm of epithelial cells, releases cytokeratin into the blood when the cells become cancerous (27), resulting in higher expression of CYFRA21-1 in serum. Involved with tumor TNM stage, duration of disease, and prognosis, the serum level of CYFRA21-1 can be used as a reference index for disease judgement (28).

The two groups of patients were comparable since they were not different in general information. According to this study, the total effective rate and local effective rate of the experimental group were significantly higher than those of the control group. In the study of Lemjabbar-Alaoui et al (29) that used gefitinib combined with GP regimen in the treatment of advanced NSCLC, the efficacy was greatly improved, the adverse reactions caused by chemotherapy drugs were reduced, along with a significantly improved patient prognosis. Jiang and Zhou (30) considered that gefitinib had better efficacy and tolerance than the traditional chemotherapy for patients with advanced NSCLC. Such previous studies, together with the result of this study, prove the good value of gefitinib for advanced NSCLC. One previous report suggests that serum tumor markers can reflect the process of malignant tumor cell transformation, and the detection of tumor marker expression has a good effect on tumor diagnosis, efficacy and prognosis evaluation (31). The study by Clifford et al (32) showed that EGFR, an expression product of proto-oncogene c-erbB1 activation that is highly expressed in various tumors such as lung cancer, and is closely related to tumor cell proliferation, invasion and metastasis. One study also found that CYFRA21-1 had a high sensitivity to the diagnosis of NSCLC, with an increase of serum concentration as the disease progressed (33). According to this study, after treatment, the expression levels of EGFR and CYFRA21-1 in the experimental and control groups were significantly lower than those in the two groups before treatment, with much lower expression levels of EGFR and CYFRA21-1 in the experimental group than in the control group, indicating the strong inhibition by gefitinib on the expression of EGFR and CYFRA21-1. The subgroups by efficacy showed the serum expression levels of EGFR and CYFRA21-1 in the effective group after treatment were significantly lower than those before treatment. The serum expression levels of EGFR and CYFRA21-1 in the ineffective group were not significantly different from those before treatment. After treatment, the levels of EGFR and CYFRA21-1 in the effective group were significantly lower than those in the ineffective group, suggesting that the detection of serum levels of EGFR and CYFRA21-1 can make certain prediction of the treatment efficacy. Boulmier et al (34) reported in their study that patients with advanced NSCLC who enjoyed good efficacy from targeted therapy had much decreased serum concentration of CYFRA21-1, while patients receiving poor efficacy from targeted therapy had greatly increased serum concentration of CYFRA21-1. A previous report pointed out that, considering the much reduced EGFR expression after the targeted therapy, the peripheral blood EGFR protein expression was capable of being a molecular biological indicator for predicting and evaluating the efficacy and prognosis gefitinib had for patients with advanced NSCLC (35). Based on the follow-up and the comparison of patient survival between the two groups, the 3 -year survival rate in the experimental group was significantly higher than that in the control group, suggesting a longer survival time due to gefitinib combined with chemotherapy. Studies have reported that targeted drug treatment for EGFR mutation-positive NSCLC patients can significantly improve the patient's objective response rate and prolong the survival time (36). According to the 3-year survival rate, the experimental group was divided into the survival and non-survival groups. The single factor analysis was performed on the general data, showing that the influencing factors of the survival include the KPS score, smoking history, number of lesions, pathological stage, EGFR, and CYFRA21-1. Subsequently, the multivariate Cox regression analysis of different indicators confirmed that smoking history, a KPS score less than or equal to 60 points, multiple lesions, pathological stage IV, high expression of EGFR and CYFRA21-1 were important factors affecting the survival of advanced NSCLC. Studies have also demonstrated that the independent factors influencing the overall survival of patients include age, pathological type, number of previous chemotherapy regimens, and number of the chemotherapeutic cycles (37). Smoking history, a KSP score equal to or more than 70 points are factors affecting the prognosis of patients with locally advanced NSCLC that is not suitable for surgery (38). Further validation is needed to explore the specific risk factors that affect patients with advanced NSCLC. Some studies also stated that a decreased range equal to or $>30 \%$ in the EGFR and CYFRA21-1 levels can be used as an independent prognostic factor for patients with advanced NSCLC $(35,39)$.

This study made an exploration of the effect of gefitinib on serum EGFR and CYFRA21-1 in patients with advanced NSCLC. However, there are some limitations due to the lack of analysis of the drug tolerance in patients orally administered gefitinib and the possible bias of the experimental design of retrospective analysis.

In conclusion, gefitinib can bring significantly improved therapeutic efficacy, lower expression levels of EGFR and CYFRA21-1, and longer survival time for patients with advanced NSCLC. Indicators including confirmed smoking history, a KPS score less than or equal to 60 points, multiple lesions, pathological stage IV, high expression of EGFR and CYFRA21-1, are important factors affecting the survival of patients with advanced NSCLC.

\section{Acknowledgements}

Not applicable.

\section{Funding}

No funding was received.

\section{Availability of data and materials}

The datasets used and/or analyzed during the present study are available from the corresponding author on reasonable request. 


\section{Authors' contributions}

HR wrote the manuscript. YangH and TX were responsible for ELISA. CJ and YanpingH analyzed and interpreted the patients' data. BY helped with statistical analysis. All the authors read and approved the final manuscript.

\section{Ethics approval and consent to participate}

The study was approved by the Ethics Committee of Hubei Cancer Hospital (Wuhan, China). Patients who participated in this research, signed the informed consent and had complete clinical data.

\section{Patient consent for publication}

Not applicable.

\section{Competing interests}

The authors declare that they have no competing interests.

\section{References}

1. Magnuson WJ, Yeung JT, Guillod PD, Gettinger SN, Yu JB and Chiang VL: Impact of deferring radiation therapy in patients with epidermal growth factor receptor-mutant non-small cell lung cancer who develop brain metastases. Int J Radiat Oncol Biol Phys 95: 673-679, 2016.

2. Zhukovsky M, Varaksin A and Pakholkina O: Statistical analysis of observational study of the influence of radon and other risk factors on lung cancer incidence. Radiat Prot Dosimetry 160: $108-111,2014$

3. Barlesi F, Mazieres J, Merlio JP, Debieuvre D, Mosser J, Lena H, Ouafik L, Besse B, Rouquette I, Westeel V, et al; Biomarkers France contributors: Routine molecular profiling of patients with advanced non-small-cell lung cancer: Results of a 1-year nationwide programme of the French Cooperative Thoracic Intergroup (IFCT). Lancet 387: 1415-1426, 2016.

4. Li Y, Chen J, He Q, Ji X, Wang X, Fan C and Li G: Clinical efficacy of neoadjuvant chemotherapy regimens FLEEOX vs. XELOX in patients with initially unresectable advanced gastric cancer: A propensity score analysis. Oncotarget 8: 86886-86896, 2017.

5. Goldberg SB, Gettinger SN, Mahajan A, Chiang AC, Herbst RS, Sznol M, Tsiouris AJ, Cohen J, Vortmeyer A, Jilaveanu L, et al: Pembrolizumab for patients with melanoma or non-small-cell lung cancer and untreated brain metastases: Early analysis of a non-randomised, open-label, phase 2 trial. Lancet Oncol 17: 976-983, 2016.

6. Lazaro T and Brastianos PK: Immunotherapy and targeted therapy in brain metastases: Emerging options in precision medicine. CNS Oncol 6: 139-151, 2017.

7. Antonoff MB and D'Cunha J: Non-small cell lung cancer: The era of targeted therapy. Lung Cancer (Auckl) 3: 31-41, 2012.

8. Yu Q, Guo Q, Chen L and Liu S: Clinicopathological significance and potential drug targeting of $\mathrm{CDH} 1$ in lung cancer: A meta-analysis and literature review. Drug Des Devel Ther 9: 2171-2178, 2015

9. Xue R, Yang C, Zhao F and Li D: Prognostic significance of CDH13 hypermethylation and mRNA in NSCLC. Onco Targets Ther 7: 1987-1996, 2014.

10. Zhang YJ, Wen CL, Qin YX, Tang XM, Shi MM, Shen BY and Fang Y: Establishment of a human primary pancreatic cancer mouse model to examine and investigate gemcitabine resistance. Oncol Rep 38: 3335-3346, 2017.

11. Lu S, Ye M, Ding L, Tan F, Fu J and Wu B: Cost-effectiveness of gefitinib, icotinib, and pemetrexed-based chemotherapy as first-line treatments for advanced non-small cell lung cancer in China. Oncotarget 8: 9996-10006, 2017.
12. Chun SG, Hu C, Choy H, Komaki RU, Timmerman RD, Schild SE, Bogart JA, Dobelbower MC, Bosch W, Galvin JM, et al: Impact of intensity-modulated radiation therapy technique for locally advanced non-small-cell lung cancer: A secondary analysis of the NRG oncology RTOG 0617 randomized clinical trial. J Clin Oncol 35: 56-62, 2017.

13. Wang J, Zuo Z, Zhang H, Li W and Wang K: Comparison of clinical outcomes of VATS and SBRT in the treatment of NSCLC. Zhongguo Fei Ai Za Zhi 19: 136-146, 2016 (In Chinese).

14. D'Oronzo S, Brown J and Coleman R: The role of biomarkers in the management of bone-homing malignancies. J Bone Oncol 9: $1-9,2017$.

15. Movsas B, Hu C, Sloan J, Bradley J, Komaki R, Masters G, Kavadi V, Narayan S, Michalski J, Johnson DW, et al: Quality of life analysis of a radiation dose-escalation study of patients with non-small-cell lung cancer: A secondary analysis of the radiation therapy oncology group 0617 randomized clinical trial. JAMA Oncol 2: 359-367, 2016.

16. Tang QF, Zhou ZW, Ji HB, Pan WH and Sun MZ: Value of serum marker HE4 in pulmonary carcinoma diagnosis. Int J Clin Exp Med 8: 19014-19021, 2015.

17. Girotti MR, Saturno G, Lorigan P and Marais R: No longer an untreatable disease: How targeted and immunotherapies have changed the management of melanoma patients. Mol Oncol 8: 1140-1158, 2014.

18. Hu XQ, Sun Y, Lau E, Zhao M and Su SB: Advances in synergistic combinations of Chinese herbal medicine for the treatment of cancer. Curr Cancer Drug Targets 16: 346-356, 2016.

19. Zhang H, Jiang H1, Hu X and Jia Z: Aidi injection combined with radiation in the treatment of non-small cell lung cancer: $A$ meta-analysis evaluation the efficacy and side effects. J Cancer Res Ther 11: 118-121, 2015.

20. Shtivelman E, Hensing T, Simon GR, Dennis PA, Otterson GA, Bueno R and Salgia R: Molecular pathways and therapeutic targets in lung cancer. Oncotarget 5: 1392-1433, 2014.

21. Enomoto Y, Kenmotsu H, Watanabe N, Baba T, Murakami H, Yoh K, Ogura T, Takahashi T, Goto K and Kato T: Efficacy and safety of combined carboplatin, paclitaxel, and bevacizumab for patients with advanced non-squamous non-small cell lung cancer with pre-existing interstitial lung disease: A retrospective multi-institutional study. Anticancer Res 35: 4259-4263, 2015.

22. Yin ZJ, Tu HY, Fu M, Zhong WZ, An SJ, Yan HH, Chen HJ, Lin HR and Wu YL: Impact of menopausal status and HER-2/neu protein on efficacy of EGFR-TKI in EGFR mutant patients with non-small cell lung cancer. J Cancer 9: 2987-2993, 2018.

23. Richter I, Dvořák J, Jirásek T and Bartoš J: The possibility of epidermal growth factor receptor inhibition in anal cancer. Klin Onkol 28: 260-264, 2015.

24. Suzuki S, Dobashi Y, Sakurai H, Nishikawa K, Hanawa M and Ooi A: Protein overexpression and gene amplification of epidermal growth factor receptor in nonsmall cell lung carcinomas. An immunohistochemical and fluorescence in situ hybridization study. Cancer 103: 1265-1273, 2005.

25. Italiano A, Vandenbos FB, Otto J, Mouroux J, Fontaine D, Marcy PY, Cardot N, Thyss A and Pedeutour F: Comparison of the epidermal growth factor receptor gene and protein in primary non-small-cell-lung cancer and metastatic sites: Implications for treatment with EGFR-inhibitors. Ann Oncol 17: 981-985, 2006.

26. Eberhard DA, Giaccone G and Johnson BE; Non-Small-Cell Lung Cancer Working Group: Biomarkers of response to epidermal growth factor receptor inhibitors in Non-Small-Cell Lung Cancer Working Group: Standardization for use in the clinical trial setting. J Clin Oncol 26: 983-994, 2008.

27. Lakayan D, Haselberg R, Gahoual R, Somsen GW and Kool J: Affinity profiling of monoclonal antibody and antibody-drug-conjugate preparations by coupled liquid chromatography-surface plasmon resonance biosensing. Anal Bioanal Chem 410: 7837-7848, 2018.

28. Alm El-Din MA, Farouk G, Nagy H, Abd Elzaher A and Abo El-Magd GH: Cytokeratin-19 fragments, nucleosomes and neuron-specific enolase as early measures of chemotherapy response in non-small cell lung cancer. Int J Biol Markers 27: e139-e146, 2012.

29. Lemjabbar-Alaoui H, Hassan OU, Yang YW and Buchanan P: Lung cancer: Biology and treatment options. Biochim Biophys Acta 1856: 189-210, 2015.

30. Jiang $T$ and Zhou C: Research progress of targeted therapy in non-small cell lung cancer brain metastases. Zhongguo Fei Ai Za Zhi 17: 824-828, 2014 (In Chinese). 
31. Slosberg ED, Kang BP, Peguero J, Taylor M, Bauer TM Berry DA, Braiteh F, Spira A, Meric-Bernstam F, Stein S, et al: Signature program: A platform of basket trials. Oncotarget 9: 21383-21395, 2018.

32. Clifford R, Govindarajah N, Parsons JL, Gollins S, West NP and Vimalachandran D: Systematic review of treatment intensification using novel agents for chemoradiotherapy in rectal cancer. Br J Surg 105: 1553-1572, 2018.

33. Xue F, Zhu L, Wang L and Wang Q: Serum neuron specific enolase levels correlate with patient prognosis for advanced lung cancer. Int J Clin Exp Med 8: 9498-9504, 2015.

34. Boulmier A, Feng X, Oms O, Mialane P, Rivière E, Shin CJ, Yao J, Kubo T, Furuta T, Oldfield E, et al: Anticancer activity of polyoxometalate-bisphosphonate complexes: Synthesis, characterization, in vitro and in vivo results. Inorg Chem 56: 7558-7565, 2017.

35. Li B, Wang Y, Zhu HX, Li JL, Hu XS, Wang B, Hao XZ, Wang L, Zhang XR and Shi YK: Association of serum EGFR protein concentration with the efficacy of gefitinib in the treatment of advanced non-small cell lung cancer. Zhonghua Zhong Liu Za Zhi 33: 431-435, 2011 (In Chinese).

36. Johnson JR, Cohen M, Sridhara R, Chen YF, Williams GM, Duan J, Gobburu J, Booth B, Benson K, Leighton J, et al: Approval summary for erlotinib for treatment of patients with locally advanced or metastatic non-small cell lung cancer after failure of at least one prior chemotherapy regimen. Clin Cancer Res 11: 6414-6421, 2005.
37. Wang L, Li Y, Li L, Wu Z, Yang D, Ma H and Wang D: The effect of icotinib combined with chemotherapy in untreated non-small-cell lung cancer that harbored EGFR-sensitive mutations in a real-life setting: A retrospective analysis. OncoTargets Ther 11: 2345-2353, 2018.

38. Filosso PL, Sandri A, Oliaro A, Filippi AR, Cassinis MC, Ricardi U, Lausi PO, Asioli S and Ruffini E: Emerging treatment options in the management of non-small cell lung cancer. Lung Cancer (Auckl) 2: 11-28, 2011.

39. Wang J, Chen J, Guo Y, Wang B and Chu H: Strategies targeting angiogenesis in advanced non-small cell lung cancer. Oncotarget 8: 53854-53872, 2017.

This work is licensed under a Creative Commons Attribution-NonCommercial-NoDerivatives 4.0 International (CC BY-NC-ND 4.0) License. 